\title{
A contemporary look at thyroid nodule management
}

\author{
What every Saudi physician and surgeon should know
}

\author{
Mazin Merdad, MD, MPH.
}

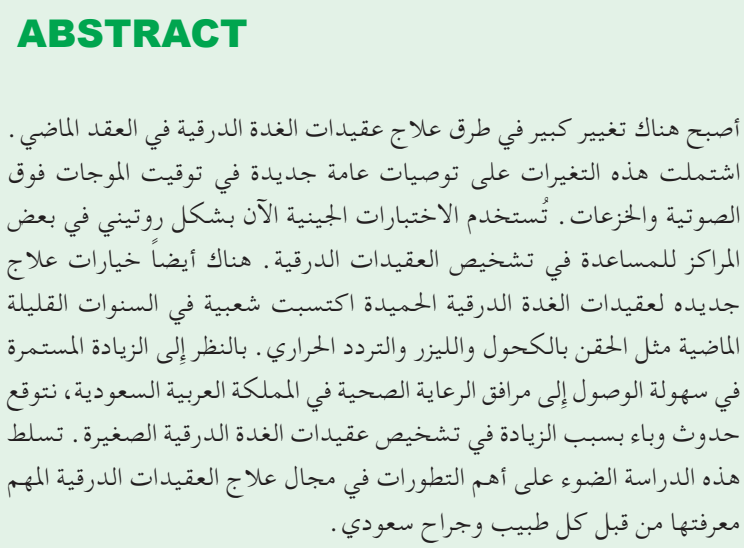

There has been substantial changes to the methods of thyroid nodule management in the past decade, including new guidelines for performing thyroid ultrasound and biopsy. Genetic tests are now routinely used in some centers to aid in the diagnosis of thyroid nodules. Novel management options, including alcohol, laser, and radio frequency ablation have also gained popularity in the past few years. Considering the continuous increase in access to healthcare facilities in Saudi Arabia, we are expecting an upcoming epidemic of small incidentally detected thyroid nodules. This study highlights the major recent advancements in thyroid nodule management that are relevant to every Saudi physician and surgeon.

Keywords: thyroid, nodule, management, Saudi Arabia

Saudi Med J 2020; Vol. 41 (2):123-127 doi: 10.15537/smj.2020.2.24899

From the Department of Otolayrngology-Head and Neck Surgery, Faculty of Medicine, King Abdulaziz University, Jeddah, Kingdom of Saudi Arabia.

Address correspondence and reprint request to: Dr. Mazin Merdad, Department of Otolaryngology-Head and Neck Surgery, Faculty of Medicine, King Abdulaziz University, Jeddah, Kingdom of Saudi Arabia.E-mail:mazin.merdad@gmail.com

ORCID ID: https://orcid.org/0000-0003-1535-113X
$\mathrm{T}$ hyroid nodules are a commonly encountered human pathology. While some nodules are visible externally showing a lump in the lower neck, others are small and only detected radiologically. It is estimated that $50 \%$ of the population harbor thyroid nodules and more than $90 \%$ of them are benign. ${ }^{1,2}$ Management of thyroid nodules has changed substantially over the past decade. Historically, most patients with thyroid nodules were offered total thyroidectomy in a onesize-fits-all approach. While thyroid surgery generally achieves high cure rates, it still carries a risk, albeit low, of complications, including recurrent laryngeal nerve injury, hypocalcemia, postoperative airway emergencies, and an unpleasantly looking scar. The contemporary management is currently quite different with each patient being offered a treatment option that is specific to his or her nodule risk of malignancy and recurrence in more a "bespoke" fashion.

It is estimated that a new peer-reviewed thyroidrelated publication is added to the literature every hour. This review aims to highlight the main transitions in thyroid nodule management that have occurred over the past decade and their relevance to our practice in Saudi Arabia.

Most thyroid nodules are discovered incidentally. Thyroid nodules are a common finding in the human thyroid gland. It is estimated that up to $50 \%$ of the population have thyroid nodules diagnosed on ultrasound screening, and the prevalence of nodules is higher in females and older patients. ${ }^{1,2}$ The higher definition of newer radiological imaging, mainly ultrasonographic machines, has contributed to the increase in thyroid nodule detection. ${ }^{3}$ Further, as access to healthcare facilities increases because of the increase in the number of facilities, health insurance coverage, and health literacy, the amount of detected incidental thyroid nodules in Saudi Arabia is expected to rise.

A good ultrasound report can estimate a nodule's risk of malignancy and guide biopsies. Previous thyroid guidelines assessed the risk of a nodule's malignancy based on fine needle aspiration biopsy (FNAB) results 
using the maximum nodule diameter as a cut-off for when a biopsy is indicated. ${ }^{3}$ Recent research; however, has shown that similar to FNAB, certain ultrasonographic features can aid in the diagnosis of thyroid cancer. ${ }^{4}$ For example, almost all papillary thyroid cancers are hypoechoic in nature, and findings, such as irregular margins and microcalcifications, further increase the potential malignancy. ${ }^{4}$ Radiologists can use these specific nodule characteristics to calculate a general malignancy risk that is specific to each nodule.

The American Thyroid Association guidelines recommends basing on the decision to perform FNAB on sonographic features in conjunction with size. ${ }^{3}$ Similarly, the European Thyroid Imaging Reporting and Data System (EU-TIRADS) uses certain nodule features to estimate the risk of malignancy in a nodule (Table 1). ${ }^{4}$

Low risk nodules carry a $0 \%$ to $4 \%$ risk of malignancy and tend to be hyperechoic or cystic, have smooth borders, and lack microcalcifications. High risk nodules are often solid, hypoechoic, and may have irregular margins or microcalcifications. In turn, they carry a $26 \%$ to $87 \%$ malignancy risk. Most guidelines limit the use of FNAB to nodules $>1 \mathrm{~cm}$ regardless of its sonographic features. ${ }^{3,4}$ Radiologists are urged to adhere

Table 1 - European Thyroid Imaging Reporting and Data System categories and malignancy risk. ${ }^{4}$

\begin{tabular}{|c|c|c|}
\hline Category & Ultrasound features & $\begin{array}{l}\text { Malignancy } \\
\text { risk, \% }\end{array}$ \\
\hline $\begin{array}{l}\text { EU-TIRADS 1: } \\
\text { normal }\end{array}$ & No nodules & None \\
\hline $\begin{array}{l}\text { EU-TIRADS 2: } \\
\text { benign }\end{array}$ & $\begin{array}{c}\text { Pure cyst } \\
\text { Entirely spongiform }\end{array}$ & $\cong 0$ \\
\hline \multirow[t]{2}{*}{$\begin{array}{l}\text { EU-TIRADS 3: } \\
\text { low risk }\end{array}$} & $\begin{array}{c}\text { Ovoid, smooth isoechoic/ } \\
\text { hyperechoic }\end{array}$ & 2 to 4 \\
\hline & No features of high suspicion & \\
\hline \multirow[t]{2}{*}{$\begin{array}{l}\text { EU-TIRADS 4: } \\
\text { intermediate risk }\end{array}$} & $\begin{array}{l}\text { Ovoid, smooth, mildly } \\
\text { hypoechoic }\end{array}$ & 6 to 17 \\
\hline & No features of high suspicion & \\
\hline \multirow[t]{5}{*}{$\begin{array}{l}\text { EU-TIRADS 5: } \\
\text { high risk }\end{array}$} & $\begin{array}{l}\text { At least one of the following } \\
\text { features of high suspicion: }\end{array}$ & 26 to 87 \\
\hline & Irregular shape & \\
\hline & Irregular margins & \\
\hline & Microcalcifications & \\
\hline & $\begin{array}{l}\text { Marked hypoechogenicity } \\
\text { (and solid) }\end{array}$ & \\
\hline
\end{tabular}

Disclosure. Authors have no conflict of interests, and the work was not supported or funded by any drug company. to these classifications in order to ease communication between physician, simplify risk stratification, and guide case management. Furthermore, it is also important to report the 3 dimensional size of a nodule (height, width, depth) in order to accurately estimate the size and monitor its growth.

Ultrasound-guided FNAB remains the main tool for diagnosing thyroid nodules. Fine needle aspiration biopsy is a safe and reliable method for diagnosing thyroid nodules. The general risk of false positives or false negatives is extremely low. ${ }^{5}$ The Bethesda classification is a widely utilized cytopathological classification system for thyroid FNAB. ${ }^{5}$ Each Bethesda category carries a certain malignancy risk and offers management recommendations (Table 2).

Just as with the EU-TIRADS classification, pathologists should adhere to the Bethesda classification to ease communication between physician, simplify risk stratification, and guide case management. ${ }^{5}$

Genetic tests are available for aiding the diagnosis of intermediate thyroid nodules (FNAB with atypia and follicular neoplasms). Fine needle aspiration biopsy categorized as atypia of undetermined significancel follicular lesion of undetermined significance or follicular neoplasm/suspicious for follicular neoplasm are considered intermediate nodules, and carry a risk of malignancy ranging from $6 \%$ to $40 \% .^{5}$ The classic treatment options for these nodules include repeating the FNAB or surgery (mostly diagnostic hemithyroidectomy, also known as thyroid lobectomy).

In the past decade, new thyroid genetic tests have gained popularity and became commercially available.

Table 2 - The 2017 Bethesda System for Reporting Thyroid Cytopathology: implied risk of malignancy and recommended clinical management. ${ }^{5}$

\begin{tabular}{|c|c|c|}
\hline Diagnostic category & $\begin{array}{c}\text { Risk of } \\
\text { malignancy, \% }\end{array}$ & $\begin{array}{c}\text { Usual } \\
\text { management }\end{array}$ \\
\hline $\begin{array}{l}\text { Non-diagnostic or } \\
\text { unsatisfactory }\end{array}$ & 5 to 10 & $\begin{array}{l}\text { Repeat FNA with } \\
\text { ultrasound guidance }\end{array}$ \\
\hline Benign & 0 to 3 & $\begin{array}{l}\text { Clinical and } \\
\text { sonographic follow-up }\end{array}$ \\
\hline $\begin{array}{l}\text { Atypia of undetermined } \\
\text { significance or follicular } \\
\text { lesion of undetermined } \\
\text { significance }\end{array}$ & 6 to 18 & $\begin{array}{l}\text { Repeat FNA, } \\
\text { molecular testing, or } \\
\text { lobectomy }\end{array}$ \\
\hline $\begin{array}{l}\text { Follicular neoplasm or } \\
\text { suspicious for a follicular } \\
\text { neoplasm }\end{array}$ & 10 to 40 & $\begin{array}{l}\text { Molecular testing, } \\
\text { lobectomy }\end{array}$ \\
\hline Suspicious for malignancy & 45 to 60 & $\begin{array}{l}\text { Total thyroidectomy } \\
\text { or lobectomy }\end{array}$ \\
\hline Malignant & 94 to 96 & $\begin{array}{c}\text { Total thyroidectomy } \\
\text { or lobectomy }\end{array}$ \\
\hline
\end{tabular}


The genetic tests are carried out on thyroid cells taken from routine FNAB. Two of the most commonly studied and utilized tests are Afirma (Veracyte, San Francisco, CA) and ThyroSeq (UPMC, Pittsburgh, PA). Afirma is a gene expression classifier (mRNA expression) used as a rule-out test to establish the benign nature of a nodule and rule out cancer. The test has a sensitivity of $92 \%$ and a negative predictive value of $93 \% .{ }^{6}$ ThyroSeq is a gene mutation test used as a rule-in test for establishing the malignancy of a nodule. It has a specificity ranging from $86 \%$ to $100 \%$ and a positive predictive value of $84 \%$ to $100 \% .^{3}$ Both tests are routinely used in a significant number of American and European centers, and they have been shown to be considerably more cost-effective when compared to diagnostic hemithyroidectomy in managing intermediate thyroid nodules. ${ }^{7}$

The Afirma test is currently available in some centers in Saudi Arabia, and its cost is covered only by the highest bracket of health insurance. For patients who pay out-of-pocket the cost ranges between SR8,000 and 12,000 , depending on the local distributor. The costbenefit results noticed in the United States might not yet apply to the healthcare system in Saudi Arabia given the local relatively low cost of surgery and high cost of the genetic tests.

Symptomatic benign thyroid nodules can be safely treated with options other than surgery. Not all thyroid nodules need to be excised, particularly when they are benign and asymptomatic. The risk of FNAB false negativity in benign thyroid nodules is $<3 \%$. According to the guidelines benign and asymptomatic thyroid nodules can be safely observed, even when the nodule is $>4 \mathrm{~cm} .{ }^{3}$ Nonetheless, before deciding on observing a nodule without any surgical intervention, it is important to thoroughly examine all of the radiological features of a nodule (echogenicity, shape of the border, microcalcifications) and rule-out the presence of any adversary radiological features.

For the symptomatic benign thyroid nodules (compressive symptoms or cosmetic reasons), the classic treatment option is thyroid surgery (total thyroidectomy or hemithyroidectomy) based on the presence or absence nodules on the contralateral lobe. Novel treatment options, such as alcohol, radiofrequency, and laser ablation techniques, have recently gained popularity as alternative treatment options for symptomatic and benign thyroid nodules.

Recent data have shown that purely cystic and partially cystic thyroid nodules can be safely and reliably treated with alcohol ablation. ${ }^{8}$ The ablation is carried out under ultrasound guidance through needle aspiration of all the fluid content and injecting the nodule cavity with concentrated alcohol. The alcohol is fully aspirated in 2 to 3 minutes; thus, causing the cyst wall to adhere to itself. The average volume reduction after alcohol ablation is between $85 \%$ and $95 \%$, and $<30 \%$ of ablated patients have a recurrence requiring further intervention. ${ }^{8,9}$

Laser ablation and radiofrequency ablation (RFA), while not yet popular options, are safe and reliable methods for managing symptomatic, solid, and benign thyroid nodules. ${ }^{10,11}$ Through a small skin puncture, the laser or RFA probes are advanced with ultrasonographic guidance into the nodule, and multiple areas are sequentially ablated. The average reduction in nodule size with RFA is $80 \%$, and long-term data does not show any significant regrowth. ${ }^{10}$

The incidence of papillary thyroid cancer is on the rise. Papillary thyroid cancer (PTC) represents more than $85 \%$ of all thyroid cancers. The incidence of PTC has been globally increasing since the late 1980's. In the United States, the overall incidence +of PTC increased from 4.9/100,000 population in the early 1990s to $14.7 / 100,000$ population in the early 2010s; a 3-fold increase over 3 decades. ${ }^{12}$ Papillary thyroid cancer is considered the most rapid growing tumor in the United States in terms of incidence, and small thyroid nodules $(<2 \mathrm{~cm}$ maximum diameter) are considered the main driver of this increasing incidence. ${ }^{12}$ Interestingly, there has been no observed matching increase in the mortality rates related to thyroid cancer within the same time period. ${ }^{12}$ The increase in incidence is hence mainly attributed to the over diagnosis of small thyroid nodule caused by the increase in access to healthcare and utilization of radiological investigations. ${ }^{13}$

For example, the Republic of South Korea initiated a universal cancer screening program in 1999 including thyroid ultrasound as an optional choice. The incidence of PTC has increased more than 15-fold since the initiation of the program, and similar to the data from the United States, the rise in PTC incidence was mainly driven by nodules $<2 \mathrm{~cm} .{ }^{14}$

As access to healthcare increases in Saudi Arabia, and more citizens and expatriates gain access to healthcare insurance, it is anticipated that we will encounter a further rise in the incidence of small thyroid cancers.

Complications related to thyroid surgery are inversely related to the surgeon's volume of thyroid surgery.

A clear correlation exists between thyroid surgery volume and patient's outcomes. Studies have shown that high-volume thyroid surgeons (surgeons performing $>40$ or more thyroid surgeries a year) have a rate of surgical complications that is $50 \%$ less than 
low-volume surgeons. ${ }^{15,16}$ In addition, surgeons are occasionally confronted with intraoperative findings, such as central neck lymphadenopathy and recurrent laryngeal nerve or tracheal wall invasion, that require special training and skills to properly address. In order to avoid future local and regional recurrences, surgeons must have special skills in neck dissection and microscopic repair of nerves. Selective "cherry picking" of only the palpable lymph nodes in cases with cervical lymph node metastasis significantly increases the risk of requiring further surgeries compared to performing proper comprehensive neck dissection. ${ }^{17,18}$

When treated properly, papillary thyroid cancer carries one of the best cancer survival rates known to bumans. Papillary thyroid cancer is the predominant type of thyroid cancer, representing $>85 \%$ of all thyroid cancers. Papillary thyroid cancer remains the only cancer in which age is considered the most important survival prognosticator. The latest American Joint Commission on Cancer (AJCC) 8th edition staging system for thyroid cancer included some major changes to the staging of well differentiated thyroid cancer: A) Age stratification is now considered at 55 years old (previously 45 years old). B) Minor extrathyroidal extension identified on histopathological examination no longer upgrades the tumor to T3. C) The presence of lymph node metastasis no longer upgrades patients to stage III.

According to the staging system patients $<55$ years old are considered stage I, regardless of the $\mathrm{T}$ and $\mathrm{N}$ status if they are free of distant metastasis, and they are considered stage II only if they have distant metastasis. ${ }^{19}$ The 5-year survival rate for patients with both stages I and II PTC was approximately $100 \% .{ }^{20}$ It is of the utmost importance for physicians and surgeons to relay these close-to-normal survival rates to their patients in an effort to minimize disease-related anxiety.

Not all PTCs are real "cancers". Follicular variants of PTC (FVPTC) is a well-known thyroid cancer entity in which the tumor architecture is follicular in nature and the nuclear features are of PTC. It represents $20 \%$ to $30 \%$ of all PTCs and histologically can be classified as a encapsulated or non-encapsulated tumor. ${ }^{21}$ Encapsulated FVPTC carries a very favorable prognosis and has recently been renamed as NonInvasive Follicular Thyroid Neoplasm with Papillarylike nuclear features (NIFTP). ${ }^{21}$ The new nomenclature uses the term neoplasm instead of cancer to emphasis the indolent nature of these tumors. The risk of local recurrence in NIFTP is $<1 \%$, and these tumors could be closely observed without any postoperative adjuvant treatment. ${ }^{21}$ Pathologists are highly encouraged to use this new terminology when applicable so that this favorable diagnosis and its prognosis can be relayed to the patient.

Radioactive iodine is restricted to cases with advanced loco-regional diseases. During the past decade, the thyroid community has been attempting to restrain the routine use of radioactive iodine (RAI) as an adjuvant treatment for post-thyroid cancer surgery. The recent ATA 2015 guidelines limits the use of RAI to patients with extrathyroidal extension or significant lymph node metastasis. ${ }^{3}$ Low risk papillary, follicular, and Hürthel cell thyroid cancer patients with tumors $<4 \mathrm{~cm}$ in maximum diameter and no significant lymph node involvement have low recurrence risk whether or not they receive post-operative RAI. ${ }^{3}$ While mostly minor, RAI causes some noticeable morbidities, including xerostomia, which can be troublesome in up to $16 \%$ to $54 \%$ of patients. ${ }^{22}$ Nuclear medicine radiologists, endocrinologists, and surgeons are encouraged to follow the latest guidelines the administration of RAI.

In conclusion, there has been significant changes in thyroid nodule management in the past decade. In Saudi Arabia, the incidence of thyroid nodule detection and the subsequent diagnosis of incidental thyroid cancers is expected to rise. Genetic tests are now commercially available and may aid in the diagnosis of intermediate thyroid nodules. Guidelines are available to aid in the categorization and risk stratification of thyroid nodules based on ultrasonographic and cytopathological features. High-volume thyroid surgeons have lower risk of surgical complications compared to low-volume surgeons. Papillary thyroid cancer has an excellent prognosis, particularly in young patients and in early stages of the disease. Some PTCs are now reclassified as NIFTPs, a premalignant neoplasm and not a cancer, with an extremely low likelihood of recurrence.

Acknowledgment. The authors gratefully acknowledge American Manuscript Editors for English language editing.

\section{References}

1. Guth S, Theune U, Aberle J, Galach A, Bamberger CM. Very high prevalence of thyroid nodules detected by high frequency (13 MHz) ultrasound examination. Eur J Clin Invest 2009; 39: 699-706.

2. Jiang H, Tian Y, Yan W, Kong Y, Wang H, et al. The prevalence of thyroid nodules and an analysis of related lifestyle factors in Beijing communities. Environ Res Public Health 2016; 13: 442

3. Haugen BR, Alexander EK, Bible KC, Doherty GM, Mandel SJ, Nikiforov YE. 2015 American Thyroid Association Management Guidelines for Adult Patients with Thyroid Nodules and Differentiated Thyroid Cancer, The American Thyroid Association Guidelines Task Force on thyroid nodules and differentiated thyroid cancer. Thyroid 2016; 26: 1-133. 
4. Russ G, Bonnema SJ, Erdogan MF, Durante C, Ngu R, Leenhardt L. European thyroid association guidelines for ultrasound malignancy risk stratification of thyroid nodules in adults: the EU-TIRADS. Eur Thyroid J 2017; 6: 225-237.

5. Cibas ES, Ali SZ. The 2017 Bethesda system for reporting thyroid cytopathology. Thyroid 2017; 27: 1341-1346.

6. Alexander EK, Kennedy GC, Baloch ZW, Cibas ES, Chudova $\mathrm{D}$, Diggans J, et al. Preoperative diagnosis of benign thyroid nodules with indeterminate cytology. N Engl J Med 2012 367: 705-715.

7. Nicholson K, Roberts MS, McCoy KL, Carty SE, Yip L. Molecular Testing Versus Diagnostic Lobectomy in Bethesda III/IV Thyroid Nodules: A Cost-Effectiveness Analysis. Thyroid. 2019; 29: 1237-1243.

8. Hahn SY, Shin JH, Na DG, Ha EJ, Ahn HS, Lim HK, et al. Ethanol ablation of the thyroid nodules: 2018 consensus statement by the Korean society of thyroid radiology. Korean J Radiol 2019; 20: 609-620.

9. Suh CH, Baek JH, Ha EJ, Choi YJ, Lee JH, Kim JK, et al. Ethanol ablation of predominantly cystic thyroid nodules: Evaluation of recurrence rate and factors related to recurrence. Clinical Radiology 2015; 70; 42-47.

10. Kim JH, Baek JH, Lim HK, Ahn HS, Baek SM, Choi YJ, et al. 2017 Thyroid Radiofrequency Ablation Guideline: Korean Society of Thyroid Radiology. Korean J Radiol 2018; 19: 632-655.

11. Mauri G, Gennaro N, Lee MK, Baek JH. Laser and radiofrequency ablations for benign and malignant thyroid tumors. Int J Hyperthermia 2019; 36: 13-20.

12. Davies L, Morris LG, Haymart M, Chen AY, Goldenberg D, Morris J, et al. American Association of Clinical Endocrinologists and American College of Endocrinology Disease State clinical review: the increasing incidence of thyroid cancer. Endocr Pract 2015; 21: 686-696

13. Morris LG, Sikora AG, Tosteson TD, Davies L. The increasing incidence of thyroid cancer: the influence of access to care. Thyroid 2013; 23: 885-891.
14. Park S, Oh CM, Cho H, Lee JY, Jung KW, Jun JK, et al. Association between screening and the thyroid cancer "epidemic" in South Korea: evidence from a nationwide study. BMJ 2016; 355: i5745.

15. Liang TJ, Liu SI, Mok KT, Shi HY. Associations of volume and thyroidectomy outcomes: a nationwide study with systematic review and meta-analysis. Otolaryngol Head Neck Surg 2016; 155: 65-75.

16. Al-Qurayshi Z, Robins R, Hauch A, Randolph GW, Kandil E. Association of surgeon volume with outcomes and cost savings following thyroidectomy: a national forecast. JAMA Otolaryngol Head Neck Surg 2016; 142: 32-39.

17. Bates MF, Lamas MR, Randle RW, Long KL, Pitt SC, Schneider $\mathrm{DF}$, et al. Back so soon? Is early recurrence of papillary thyroid cancer really just persistent disease? Surgery 2018; 163: 118-123.

18. Miller JE, Al-Attar NC, Brown OH, Shaughness GG, Rosculet NP, Avram AM, et al. Location and causation of residual lymph node metastasis after surgical treatment of regionally advanced differentiated thyroid cancer. Thyroid 2018; 28: 593-600.

19. Tuttle RM, Haugen B, Perrier ND. Updated American Joint Committee on Cancer/Tumor-Node-Metastasis Staging System for Differentiated and Anaplastic Thyroid Cancer (Eighth Edition): What changed and why? Thyroid 2017; 27: 751-756.

20. National Cancer Institute. SEER Cancer Statistics Review (CSR) 1975-2015. [Updated 2018. April 2018]. Available from URL: https://seer.cancer.gov/csr/1975_2015/

21. Nikiforov YE, Seethala RR, Tallini G, Baloch ZW, Basolo F, Thompson LD, et al. Nomenclature revision for encapsulated follicular variant of papillary thyroid carcinoma: a paradigm shift to reduce overtreatment of indolent tumors. JAMA Oncol 2016; 2: 1023-1029.

22. Clement SC, Peeters RP, Ronckers CM, Links TP, van den Heuvel-Eibrink MM, Nieveen van Dijkum EJ, et al. Intermediate and long-term adverse effects of radioiodine therapy for differentiated thyroid carcinoma-a systematic review. Cancer Treat Rev 2015; 41: 925-934. 